\title{
Recent progress in non-invasive imaging of Internal body temperature using the water proton chemical shift
}

\author{
水プロトン化学シフトを用いた体内温度の非侵襲画像化における最近の進歩
}

\author{
Kagayaki KURODA ${ }^{1,2}$ \\ ${ }^{I}$ Department of Human and Information Sciences, The Faculty of Information Technology and \\ Electronics, Tokai University, 1117 Kitakaname, Hiratsuka, Kanagawa, 259-1292 Japan \\ Phone:+81-463-58-1211 (x5331)Fax:+81-463-50-2031,E-mail: kagayaki@keyaki.cc.u-tokai.ac.jp \\ ${ }^{2}$ Department of Image-based Medicine, Institute of Biomedical Research and Innovation, 2-2 \\ Minatojima-Minamimachi, Chuo, Kobe, Hyogo, 650-0047 Japan \\ Phone:+81-78-304-5200 Fax: +81-78-304-5201,E-mail: kuroda@ibri-kobe.org
}

(Received 24, December 2002 Accepted 13,February 2003)

\begin{abstract}
The water proton chemical shift observed in magnetic resonance is a measure of internal body temperature. The phase mapping method using this parameter has yielded a practical tool of non-invasive temperature imaging for monitoring thermal therapies, although the temperature coefficient of this parameter is small $\left(-0.01 \mathrm{ppm} /{ }^{\circ} \mathrm{C}\right)$.
\end{abstract}

Keywords : temperature, MRI, chemical shift, water, proton

\section{INTRODUCTION}

One of the unique features of MRI in comparison with the other imaging modalities in interventional use is the capability to image temperature. Among several MR parameters (longitudinal relaxation time, transverse relaxation time, diffusion coefficient, chemical shift etc.), the chemical shift of water proton is recognized as the most reliable indicator of temperature. Because the chemical shift is the only frequency-based parameter and is independent of the other parameters, which are measured based on the intensity of the signal and therefore are dependent on each other in a finite repetition time. In this paper, the basic principle and recent progresses of the temperature imaging technique using the water proton chemical shift is discussed.

\section{PRINCIPLE}

Temperature dependence of the proton chemical shift occurs when the proton system under observation has hydrogen bonds. ${ }^{1}$ In biological tissues, the most abundant hydrogen-bonded proton system is water. When temperature rises, motion of water molecules intensifies breaking the hydrogen bonds among the molecules. The reduction in the hydrogen bonding strength activates the currents induced in the electron clouds around the water protons strengthening the effect of shielding the external magnetic field. As the result, the magnetic resonance frequency of the water proton becomes lower. The chemical shift is defined as the ratio between the frequency shift and a reference. The decay rate of the water proton chemical shift is -0.01 $\mathrm{ppm} /{ }^{\circ} \mathrm{C}$ in pure water. ${ }^{1}$ This value is quite similar in the tissue water in various organs. ${ }^{2-5}$

The macroscopic change in the water proton chemical shift in a voxel can be transcribed into the change in the phase angle of the macroscopic magnetization of the voxel. ${ }^{4}$ This can be achieved by using gradient-echo-based sequences with moderate echo time (TE). The change in the temperature $(\Delta T)$ is denoted by the following equation;

$\Delta T=\Delta \delta / \alpha=\Delta \phi /\left(\alpha \cdot 2 \pi \cdot f_{0} \cdot T E\right)$

where $\Delta \delta$ is the change in the water proton chemical shift [ppm], $\alpha$ is the temperature coefficient of the water proton chemical shift $\left[\mathrm{ppm} /{ }^{\circ} \mathrm{C}\right], \Delta \phi$ is the change in the phase of the signal in a voxel. As is known from this equation, relative temperature change can be imaged as the change in the signal phase. This technique is called phase mapping method or proton resonance frequency (PRF) method. 


\section{CLINICAL AVAILABILITY}

A set of temperature images obtained with the phase mapping method on a $0.5 \mathrm{~T}$ open MRI (SignaSPi, GE Medical Systems Inc., Milwaukee, WI, USA) during a clinical case of laser ablation for brain tumor is shown in Fig. 1. The position, size and rough estimation of the temperature elevation in the brain are clearly visualized. The phase mapping method is already applied to clinical cases in several sites. $^{6-8}$

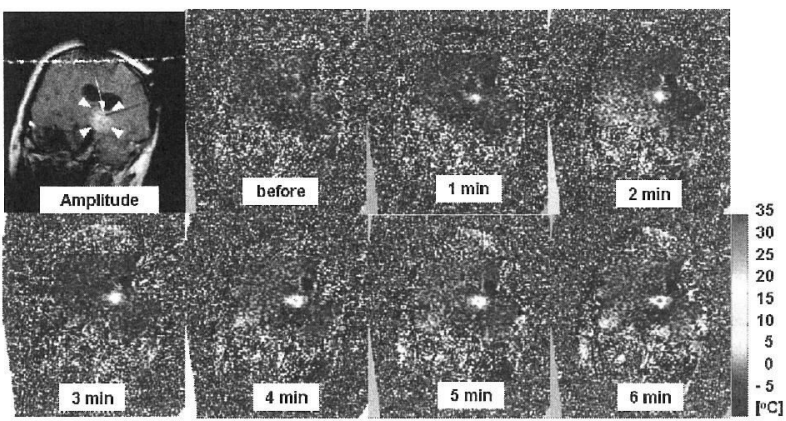

Fig.1. Coronally oriented temperature images during a 6-minute laser irradiation for a patient with a Left thalamic and hypothalamic astrocytoma of $25 \mathrm{~mm} \times 20 \mathrm{~mm}$. (a) SPGR amplitude image. (b) Immediately after the laser was turned on. (c) $1 \mathrm{~min}$, (d) $2 \mathrm{~min}$, (e) $3 \mathrm{~min}$, (f) $4 \mathrm{~min},(\mathrm{~g}) 5 \mathrm{~min}$, and (h) $6 \mathrm{~min}$ later. Imaged were taken with SPGR of TR / TE, 55/14.

\section{MOTION COMPENSATION}

Since the phase mapping method uses the image subtraction to obtain the temperature-induced phase change, factors producing phase change can be source of temperature misreading. The most significant factor is motion between a pair of time points of temperature observation. There are two significant effects of the inter-scan motion: the first is the tissue translation or deformation, which makes the protons in a voxel move away to the other $\operatorname{voxel}(s)$, and the second is the deformation of the magnetic flux induced by the tissue translation and deformation. A few techniques to compensate for those motion effects in temperature imaging have been propsed. ${ }^{9-11}$ A simple technique is to hold breath at a certain reference point.

An optical displacement detection system (Anzai Medical Corp., Tokyo, Japan) was modified to operate in the gantry of the open MRI in order to achieve "quantitative" breath holding. Figure 2 shows the experimental setup to perform temperature imaging of liver under microwave ablation. The respiratory motion of a pig of $20 \mathrm{~kg}$ in weight lying in the gantry of the open magnet under general anesthesia was monitored and held in a manual manner as depicted in Fig.3. Figure 4 shows the liver temperature elevation images obtained successfully with this optically controlled breath holding technique.

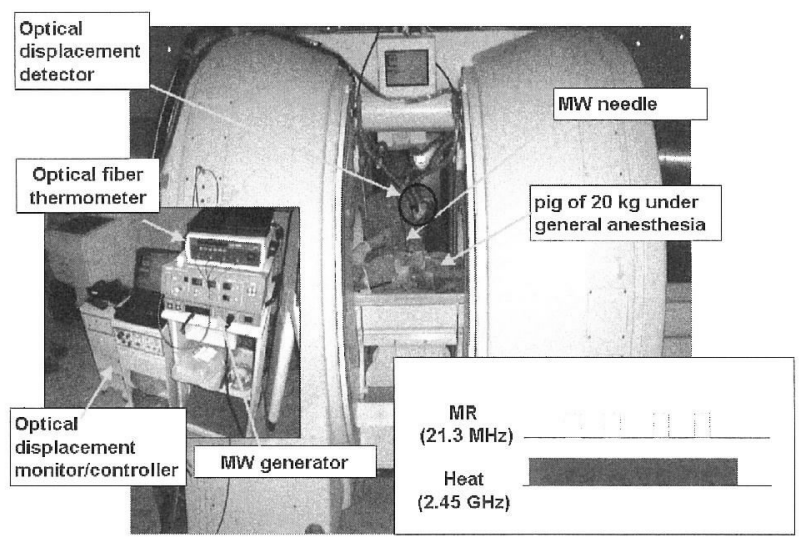

Fig.2. Experimental setup for temperature imaging of the porcine liver in vivo under microwave ablation.

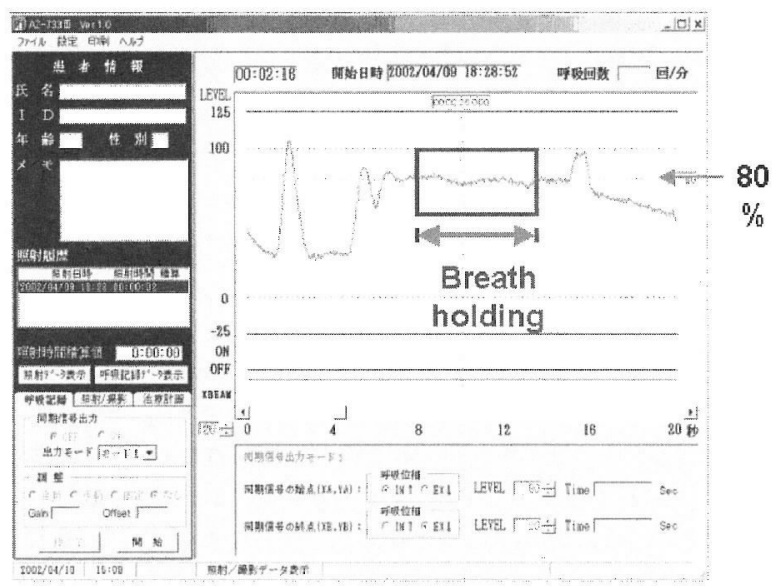

Fig.3. Optically measured displacement of the abdomen wall of the pig under general anesthesia. Temperature imaging was performed during the breath holding period.
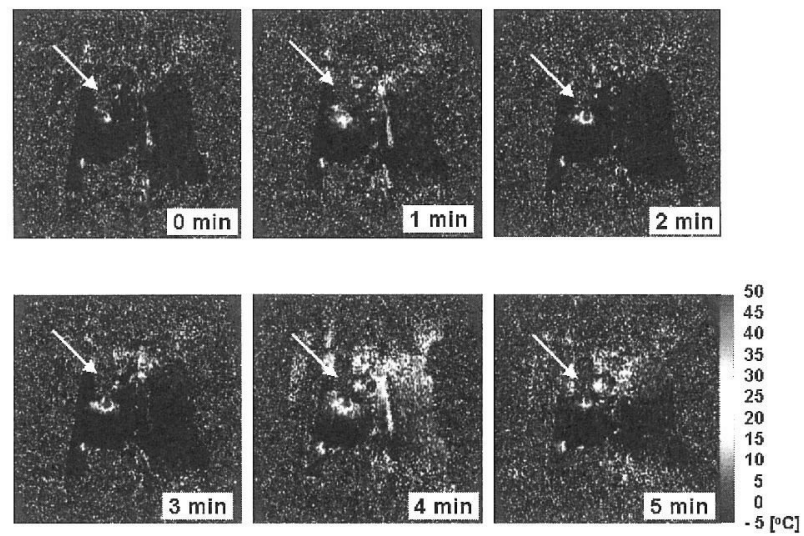

Fig.4. Temperature images of the porcine liver. The arrow indicates the tip position of the microwave needle. 


\section{THREE DIMENSIONAL IMAGING}

In the cases of thermal ablations, the temperature elevation pattern may have complicated shape depending on the target tissue region and the technique to give thermal energy to the target. Thus three dimensional structure of the high temperature region is required. Since the full volume acquisition of the temperature sensitive images takes time (imaging time per slice multiplied by the number of slices), the temperature change among the slices will degrade the accuracy of temperature imaging. Figure 5 shows our approach to approximately obtain three dimensional temperature elevation patterns with three orthogonal single slices. The sequence was implemented to the open MRI stated above. A PC-based user interface to display the temperature images as well as the specific absorption rate images has been developed. The "quasi-three-dimensional" images give sufficient information for the operator to seize the rough structure of the high temperature/dose regions. The system is currently under construction to achieve automatic feedback control of heat delivery based on the coverage of the high temperature/dose region over the target tissue volume.

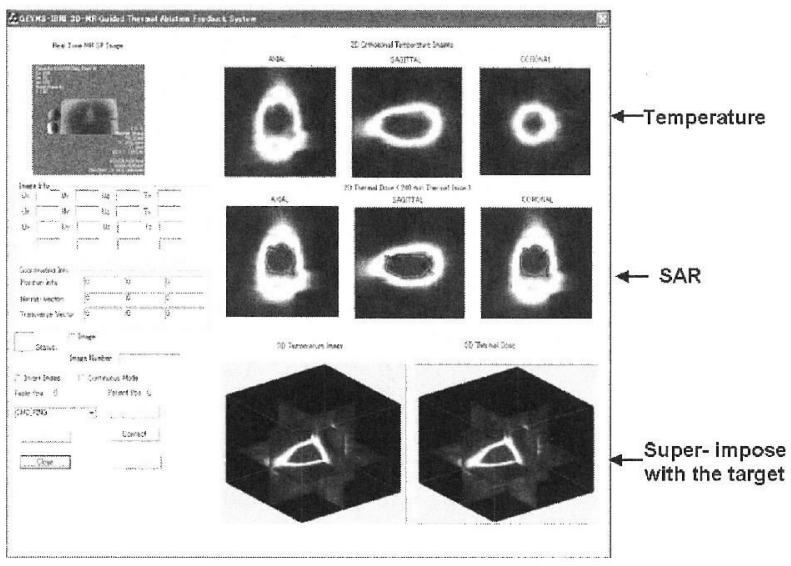

Fig.5. PC-based user interface showing the temperature images on the three orthogonal planes.

\section{VI . INTERNALLY REFERENCED TECHNIQUES}

Another approach to image temperature using the temperature dependence of the water proton chemical shift is the spectroscopic method. In this approach, it is allowed for us to use a proton component with temperature insensitive resonance frequency. The most recent ideas are adopting echo planar spectroscopic imaging (EPSI) ${ }^{12}$ or its line scan version (LSEPSI). ${ }^{13}$ Figure 6 shows the experimental setup to examine the feasibility of the method using a rabbit brain under localized laser heating. The LSEPSI sequence used is shown in Fig. 7. N-acetyl aspartate in the brain was used as the internal reference component to measure water proton chemical shift. Although the correlation of water-NAA chemical shift and temperature was ambiguous because the voxel size was far too large compared with the probing volume of the fiber-optic thermometer, the resultant temperature distribution seemed to be reasonable at least qualitatively. The data acquisition time was $8 \mathrm{~min}$ per image. The theoretical advantage of the spectroscopic method is the reduction of the effect of the inter-scan motion and susceptibility change by virtue of the internally referenced chemical shift measurement. The inherently long acquisition time, however, allows for much more chance to encounter the intra-scan motion and spoils the theoretical advantages. The spectroscopic method needs more examination to be a practical tool.

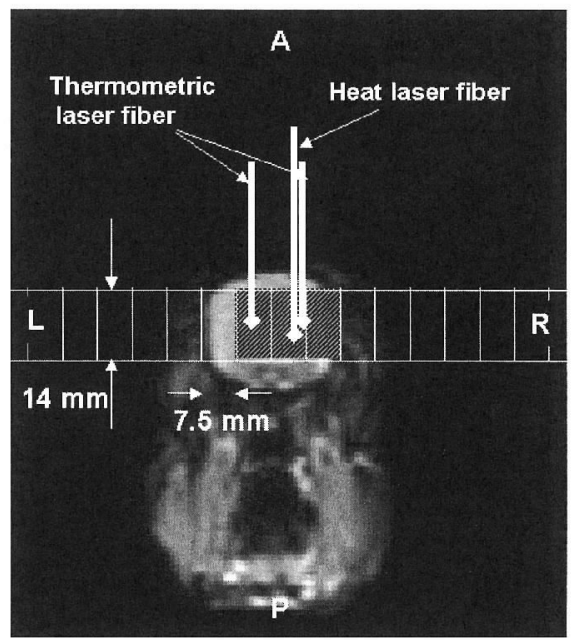

Fig.6. Experimental setup for temperature imaging using the LSEPSI method.

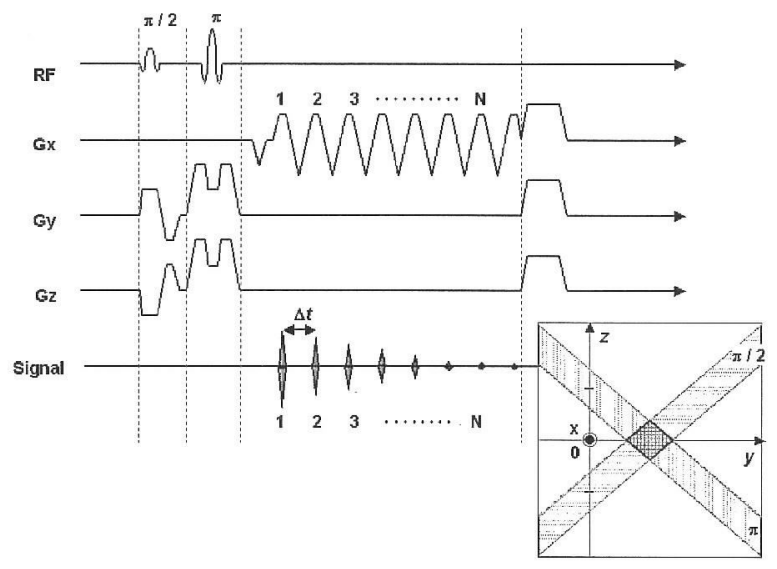

Fig.7. Sequence diagram of LSEPSI. 
The spatial deviation of the absolute values of the water-NAA chemical shift obtained before heating were as large as $0.1 \mathrm{ppm}$, which is equivalent to 10 ${ }^{\circ} \mathrm{C}$ of temperature difference. The reason for the deviation in the chemical shift is not clear yet. It may be due to a spatial distribution of water and NAA protons and / or susceptibility inside a voxel. This fact implies that the absolute value of the chemical shift can markedly deviate. The extent and the factor of this deviation make absolute temperature measurement problematic and is under investigation.

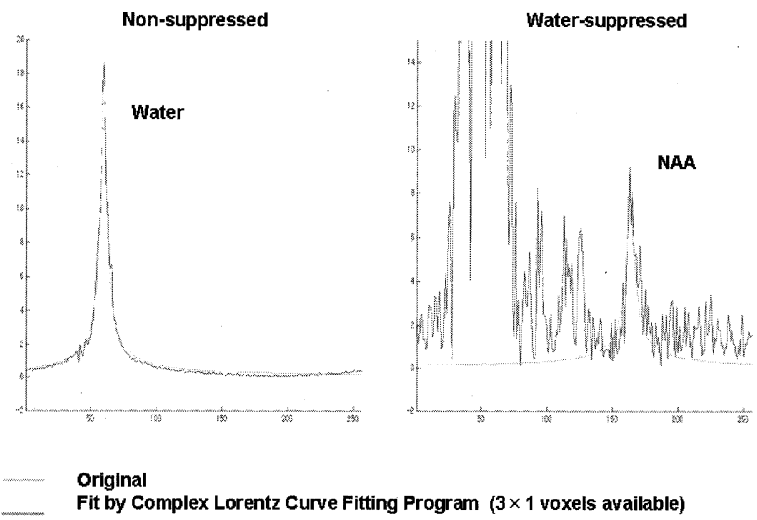

Fig.8. Proton spectra obtained from the rabbit brain in vivo.

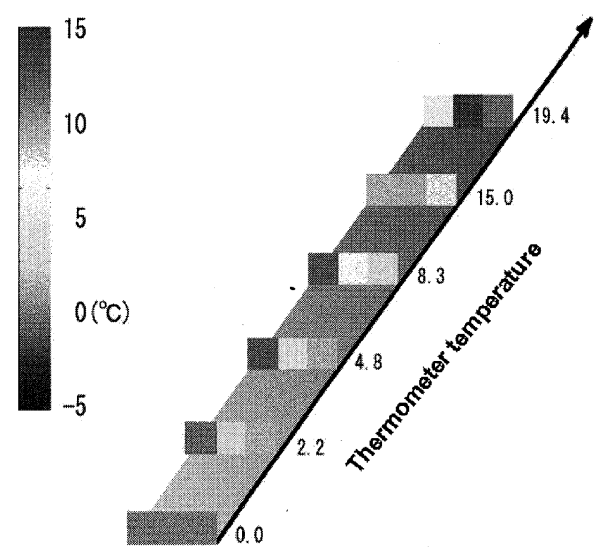

Fig.9. Temperature elevation images based on the water-NAA proton chemical shift.

\section{DISCUSSIONS}

MR temperature imaging using phase mapping method is becoming a practical tool already for monitoring and estimating the therapeutic effect of the thermal ablation procedures in limited fields, where the temperature elevation is large enough and the motion of the tissues are negligibly small. The techniques to compensate the motion and susceptibility artifact and to visualize the three dimensional structure of the temperature field are still at the experimental levels. Reduction of the acquisition time and increase of the signal to noise ratio are the primary task to be achieved for the spectroscopic approaches. It is also necessary to investigate the factors for the spatial variation of the chemical shift difference, which complicates absolute temperature measurement.

\section{ACKNOWLEDGEMENTS}

This work was supported by the medical-engineering research project of the New Energy and Industrial Technology Organization (NEDO), Japan. The author is grateful for all his colleagues working for the NEDO project.

\section{REFERENCES}

${ }^{1}$ Hindman JC. Proton resonance shift of water in gas and liquid states. J Chem Phy 1966; 44: 4582-4592.

2 Lutz KW, Kuesel AC, Hull WE, A 1H-NMR method for determining temperature in cell culture perfusion systems, Magn Reson Med 1993; 29: 113-118.

${ }^{3}$ Kuroda K, Abe K, Tsutsumi S, Ishihara Y, Suzuki $\mathrm{Y}$, Satoh K. Water proton magnetic resonance spectroscopic imaging, Biomed Thermol 1994; 13: 43-62.

${ }^{4}$ Ishihara Y, Calderon A, Watanabe $\mathrm{H}$, Okamoto K, Suzuki Y, Kuroda K, Suzuki Y. A precise and fast temperature mapping using water proton chemical shift. Magn Reson Med 1995; 34: 814-823.

${ }^{5}$ Poorter JDe, Wagter Cde, Deene De, Thomsen C, Stahlberg F, Achten E, Non-invasive MRI thermometry with the proton resonance frequency shift (PRF) method: in vivo results in human muscle. Magn Reson Med 1995; 33: 74-81.

${ }^{6}$ Moriaty JA, Chen JC, Purcell CM, Ang LC, Hinks RS, Peter RD, Henkelman RM, Plewes DB, Bronskill MJ, Kucharczyk W. MRI monitoring of interstitial microwave-induced heating and thermal lesions in rabbit brain in vivo. J Magn Reson Imag 1998; 8: 128-135.

${ }^{7}$ Kettenbach J, Silverman SG, Hata N, Kuroda K, Saiviroonporn P, Zientara GP, Morrison PR, Hushek SG, Black PM, Kikinis R, Jolesz FA. Monitoring and visualization technique for MR-guided laser ablation in an open MR system. J Magn Reson Imag 1998; 8: 933-943.

${ }^{8}$ Kahn T, Harth T, Kiwit JCW, Schawarzmaier H-J, Wald C, Mödder U. In vivo MRI thermometry using a phase-sensitive sequence: preliminary 
experience during MRI-guided laser-induced interstitial thermotherapy of brain tumors. J Magn Reson Imag 1998; 8: 160-164.

${ }^{9}$ Kuroda K, Keserci B, Harada D, Kumamoto E, Okada A, Abe $\mathrm{H}$, Tashiro $\mathrm{H}$, Motion Effect Compensation for MR Temperature Imaging, Proc. 4th Interventional MRI symposium, Leipzig 2002, P-06.

${ }^{10}$ Vigen K, Daniel B, Pauly J, Butts K, Comparison of a realtime triggered, navigated, multi-baseline PRF method with basic triggered methods for temperature mapping with respiratory motion, Proc. 4th Interventional MRI symposium, Leipzig 2002.

${ }^{11}$ Vogel M, Moelker A, Ouhlous M, Pattynama P,
Movement Registration for PRF Based MR Thermometry, Proc 11th ISMRM meeting Honolulu 2002.

${ }^{12}$ Kuroda K, Oshio K, Mulkern RV, Panych LP, Nakai T, Moriya T, Okuda S, Hynynen K, Jolesz FA, Temperature Mapping Using Water Proton Thermal Shift: Self-Referenced Method with Echo Planar Spectroscopic Imaging, Magn Reson Med 2000; 43: 220-225

${ }^{13}$ Kuroda K, Mulkern RV, Oshio K, McDannold N, Hynynen K, Nakai T, Okada T, Matsumura A, Yanaka K, Jolesz FA, Feasibility of Internally-Referenced Temperature Imaging using Metabolite Signals, Proc. 9th ISMRM Meeting, Glasgow 2001; p. 2189 